\title{
INVESTIGAÇÃO DE TOPOLOGIAS DE REDES NEURAIS ARTIFICIAIS PARA A PREVISÃO DA CINÉTICA DE SECAGEM DOS FRUTOS DE AROEIRA-VERMELHA (Schinus terebinthifolius Raddi)
}

\author{
B. G. SILVA ${ }^{1}$ e A. M. F. FILETI ${ }^{1}$ \\ ${ }^{1}$ Universidade Estadual de Campinas, Faculdade de Engenharia Química, Departamento de \\ Engenharia de Sistemas Químicos \\ E-mail para contato: b.guzzos@gmail.com
}

\begin{abstract}
RESUMO - Neste estudo, várias topologias de Redes Neurais Artificiais (RNA's) para a previsão da cinética de secagem dos frutos de aroeira-vermelha (Schinus terebinthifolius Raddi) foram investigadas. Os dados experimentais foram obtidos em um secador de leito fixo, em camada delgada, e estes foram expandidos através da interpolação por spline cúbica. Nas modelagens foram utilizadas redes do tipo feedforward formada por 3 camadas e a função de ativação dos neurônios ocultos foi a tangente hiperbólica. Para o treinamento das RNA's foi utilizado o algoritmo de Levenberg-Marquartdt com regularização bayesiana. O coeficiente de determinação $\left(\mathrm{R}^{2}\right)$ e a raiz do erro quadrático médio (RMSE) foram usados, entre outros critérios, para comparar os desempenhos das RNA's. As influências do banco de dados, dos neurônios de entrada e da função de ativação também foram investigadas. Os resultados $\left(\mathrm{R}^{2}>0,99\right.$ e $R M S E$ baixo) mostram que as RNA's representaram bem a cinética de secagem dos frutos de aroeira-vermelha.
\end{abstract}

\section{INTRODUÇÃO}

$\mathrm{Na}$ área de secagem, diversas pesquisas vêm sendo desenvolvidas focando principalmente a avaliação da cinética do processo, o que inclui o desenvolvimento de modelos matemáticos. Os modelos são primordiais em processos de secagem, pois proporciona, por exemplo: realizar estudos, em tempo real, do efeito das alterações nas condições operacionais do processo; desenvolver técnicas de otimização do processo; e auxiliar no projeto de secadores como, por exemplo, no desenvolvimento de estratégias de controle do processo (Silva et al., 2004). Afzal e Abe (2000) citam que a modelagem matemática de processos de secagem baseia-se em três categorias principais: modelos teóricos, semi-empíricos e empíricos.

O elevado número de trabalhos publicados que aplicam RNA's reflete a potencialidade desta ferramenta de modelagem empírica em diversos processos de engenharia química. Em processos de secagem, as RNA's foram pouco exploradas, sendo utilizadas, por exemplo, para modelar o processo de secagem em leito fixo de tomate (Movagharnejad e Nikzad, 2007) e para prever a cinética de secagem de resíduos sólidos orgânicos (Perazzini et al., 2013). Na modelagem por RNA's, além da alta precisão, outra vantagem é a sua 
capacidade de prever o comportamento da cinética de secagem para uma faixa operacional e não apenas para uma única condição experimental, como observado nos modelos tradicionais de secagem. Assim, as RNA's podem ser utilizadas para a estimativa on-line de parâmetros de secagem e também para o controle dos processos de secagem industriais.

Com base no que foi exposto anteriormente, o objetivo deste trabalho foi investigar topologias de RNA's para a previsão da cinética de secagem dos frutos de aroeira-vermelha. Esta matéria-prima é utilizada na produção da pimenta-rosa, um dos mais sofisticados condimentos da culinária internacional e que vem apresentando um aumento na sua demanda. $\mathrm{Na}$ literatura encontram-se poucos estudos sobre o seu processamento, em que a secagem é uma etapa indispensável e que ainda é realizada de forma empírica. Nas empresas beneficiadoras, a etapa de secagem tem por finalidade aumentar a vida de prateleira do produto, além de agregar valor aos frutos da aroeira-vermelha.

\section{MATERIAIS E MÉTODOS}

\subsection{Matéria-prima}

Os frutos de aroeira-vermelha (Schinus terebinthifolius Raddi) foram obtidas na cidade de São Mateus, no estado do Espírito Santo, no mês de junho de 2012. As amostras foram armazenadas em freezer a $-30,0^{\circ} \mathrm{C}$ e antes de cada experimento, os frutos foram classificados, descongelados e reumidificados. As amostras apresentavam as seguintes características: teor de umidade inicial, em base seca, variando entre 0,51 a 0,55 ; diâmetro médio de $0,47 \mathrm{~cm}$; e massa específica aparente de $0,56 \mathrm{~g} / \mathrm{cm}^{3}$.

\subsection{Banco de dados}

Para que a modelagem por RNA's seja eficiente, é necessário utilizar um banco de dados que garanta um mapeamento para qualquer par entrada/saída que seja introduzido na RNA e que faça parte de seu domínio. Assim, a partir dos ensaios da Tabela 1 foi organizado um banco de dados constituído por oito experimentos que foram utilizados na etapa de treinamento da RNA $(1,2,5,6,7,8,9$ e 10) e por três experimentos que foram utilizados na etapa de verificação da RNA (3, 4 e 11). O banco de dados apresenta as seguintes características: valores máximos e mínimos das variáveis operacionais na etapa de treinamento; e todos os níveis de temperatura na etapa de treinamento, pois a temperatura é a variável mais influente no processo de secagem dos frutos de aroeira-vermelha.

Os ensaios de secagem, descritos na Tabela 1, foram realizados em um secador de leito fixo, em camada delgada. De forma geral, o procedimento experimental consistiu na passagem de ar aquecido através de um leito fixo de sólidos de aproximadamente $1,0 \mathrm{~cm}$ (massa inicial do leito igual a 16,0 g). Em todos os experimentos, a massa do leito foi registrado em intervalos de 5 minutos até as 2 primeiras horas do processo, depois a cada 10 minutos até atingir as 4 horas do processo e a cada 15 minutos até que as variações da massa das amostras fossem insignificantes. Informações detalhadas da metodologia experimental e do secador são descritas no trabalho de Silva (2013). 
Tabela 1- Condições operacionais dos ensaios de secagem

\begin{tabular}{|c|c|c|c|c|}
\hline Ensaios & $\begin{array}{c}\text { Temperatura do ar } \\
\left({ }^{\circ} \mathbf{C}\right)\end{array}$ & $\begin{array}{c}\text { Velocidade do ar } \\
(\mathbf{m} / \mathbf{s})\end{array}$ & $\mathbf{X}_{\mathbf{s , o}}(\mathbf{a d i m} \mathbf{)})$ & $\mathbf{U R}(\boldsymbol{\%})$ \\
\hline 1 & 44,4 & 0,46 & 0,537 & 19,87 \\
\hline 2 & 65,6 & 0,46 & 0,553 & 7,65 \\
\hline 3 & 44,4 & 0,74 & 0,514 & 12,77 \\
\hline 4 & 65,6 & 0,74 & 0,544 & 5,97 \\
\hline 5 & 40,0 & 0,60 & 0,513 & 14,09 \\
\hline 6 & 70,0 & 0,60 & 0,540 & 3,50 \\
\hline 7 & 55,0 & 0,40 & 0,518 & 15,03 \\
\hline 8 & 55,0 & 0,80 & 0,526 & 9,64 \\
\hline 9 & 55,0 & 0,60 & 0,545 & 10,34 \\
\hline 10 & 55,0 & 0,60 & 0,533 & 12,64 \\
\hline 11 & 55,0 & 0,60 & 0,530 & 11,45 \\
\hline
\end{tabular}

Os conjuntos de treinamento e verificação da RNA foram expandidos usando interpolação de dados por spline cúbica com o auxílio do software MATLAB. Esta etapa foi realizada com o objetivo de obter dados em intervalos iguais de tempo (5 em 5 minutos). Inicialmente o banco de dados possuía 656 vetores, sendo que após a interpolação este número passou para 1286 vetores: 935 para o treinamento e 351 para a verificação da RNA. O banco de dados também foi normalizado, procurando-se desta maneira eliminar eventuais problemas relacionados às diferentes magnitudes dos dados. Para cada variável foram assumidos os valores +1 para o seu maior valor real $\left(X_{i, \text { máximo }}\right)$ e -1 para o seu menor valor real $\left(X_{i, \text { mínimo }}\right)$. Deste modo, para a transformação dos valores reais em valores codificados foi determinada a Equação 1, que relaciona as variáveis codificadas $\left(x_{i}\right)$ com as variáveis reais $\left(X_{i}\right)$.

$$
x_{i}=2\left(\frac{X_{i}-X_{i, \text { minimo }}}{X_{i, \text { máximo }}-X_{i, \text { mínimo }}}\right)-1
$$

Esta normalização foi realizada no MATLAB utilizando o comando premnmx. Os dados de saída da RNA foram desnormalizados utilizando a Equação 2, sendo que no MATLAB foi utilizado o comando postmnmx.

$$
X_{i}=\frac{\left(X_{i, \text { máximo }}-X_{i, \text { mínimo }}\right) \cdot\left(x_{i}+1\right)}{2}+X_{i, \text { mínimo }}
$$

\subsection{Topologias de RNA's}

Neste trabalho, várias topologias de RNA's (Figura 1), comumente aplicadas a modelagem de processos de secagem, foram investigadas e suas performances de previsão foram avaliadas para definir o modelo mais adequado. 


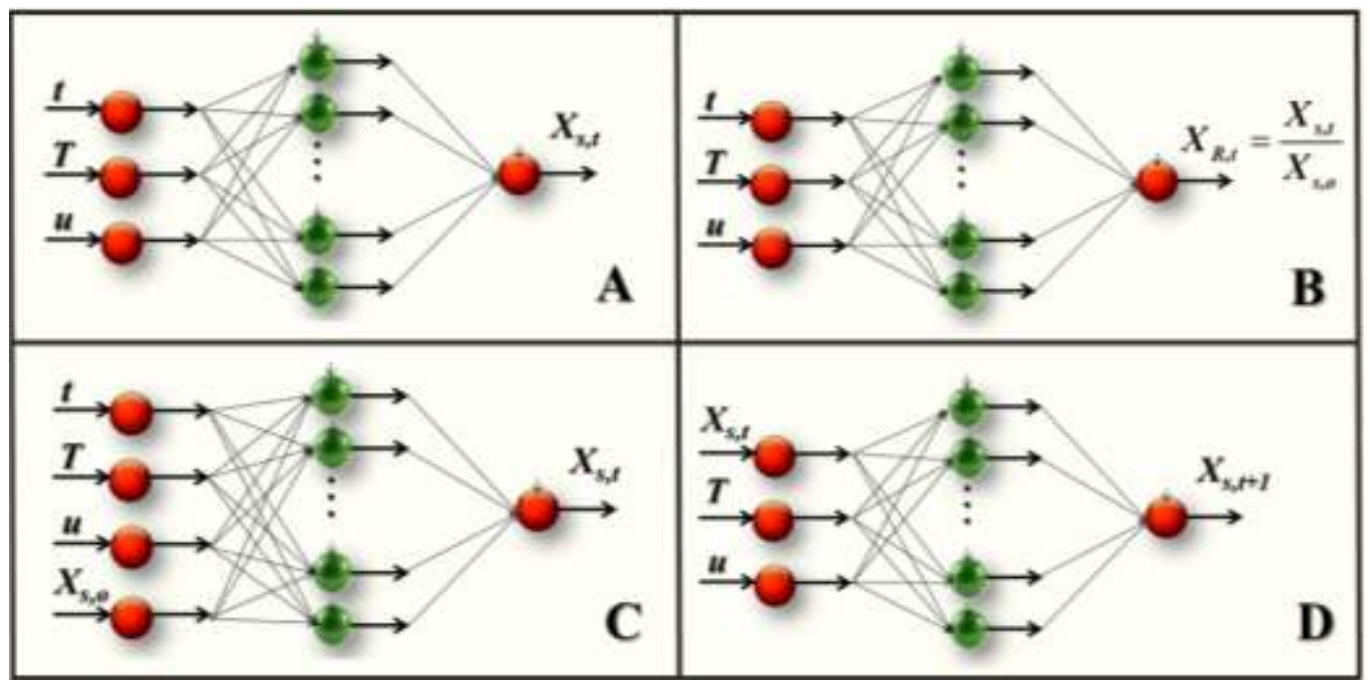

Figura 1 - Topologias de RNA's utilizadas para a modelagem da cinética de secagem.

Na Figura 1, $t$ é o tempo de secagem, $T$ é a temperatura do ar, $u$ é a velocidade do ar de secagem, $X_{R, t}$ é o adimensional de umidade dos frutos, $X_{s, t}$ é o teor médio de umidade dos frutos, em base seca, e $X_{s, o}$ é o teor de umidade inicial dos frutos, em base seca. Conforme observado na Figura 1, em todas as topologias a temperatura e a velocidade foram utilizadas como entrada da RNA. Observa-se também que nas topologias A, B e C o tempo foi utilizado como uma das entradas da rede, conforme relatado nos trabalhos de Movagharnejad e Nikzad (2007), Ceylan (2008), Topuz (2010), Singh e Pandei (2011), Balbay et al. (2011) e Perazzini et al. (2013). Na topologia D não foi utilizado o tempo como entrada da RNA e sim o teor de umidade em um momento antes da saída prevista pela rede, conforme utilizado na RNA desenvolvida por Kaminski et al. (1998).

Para realizar as modelagens e simulações, foi utilizado como ferramenta computacional o software MATLAB (Neural Network Toolbox). O programa desenvolvido apresenta, de forma geral, as seguintes etapas: carregamento do banco de dados; normalização dos dados; divisão dos dados (treinamento e verificação); definição da arquitetura da RNA; treinamento; e verificação da RNA. Em todas as modelagens investigadas foi utilizada uma RNA do tipo feedforward (newff no software MATLAB) formada por três camadas: uma camada de entrada; uma camada oculta; e uma camada de saída. Na camada oculta, a função de ativação dos neurônios foi a função tangente hiperbólica (tansig no software MATLAB). Já a função de ativação utilizada no neurônio da camada de saída foi a função linear (purelin no software MATLAB). Em cada topologia de RNA, o número de neurônios da camada oculta foi determinado buscando-se um ajuste eficaz do modelo neural aos dados de verificação. Deste modo, durante as modelagens o número de neurônios ocultos foi aumentado e para cada número fixo de neurônios foram realizados vários treinamentos até encontrar o melhor ajuste da RNA aos dados de verificação.

Para a etapa de treinamento da RNA, foi utilizado o algoritmo de treinamento de Levenberg-Marquartdt com regularização bayesiana (função trainbr no software MATLAB), pois esta técnica evita o sobreajuste de dados. A raiz do erro quadrático médio (RMSE) de cada modelagem foi calculada conforme a Equação 4, tanto para a etapa de treinamento como para a etapa de verificação da rede. 
$R M S E=\sqrt{\frac{\sum_{i=1}^{N} e_{i}^{2}}{N}}$

Em que $\sum_{i=1}^{N} e_{i}^{2}$ é o somatório do erro ao quadrado e $N$ é a quantidade de vetores utilizados em cada etapa (treinamento ou verificação). Após a etapa de treinamento, foi realizada a etapa de verificação da rede, sendo apresentados novos dados de entrada, obtendose assim, por simulação, os dados de saída desejados. O valor determinado através do modelo neural foi então comparado ao valor real através da análise dos gráficos de dispersão (dados reais de verificação versus preditos pelo modelo). Quando os dados se apresentavam na forma de uma reta coincidente com a diagonal, em que o coeficiente linear se aproximava de zero e o coeficiente angular e o $\mathrm{R}^{2}$ fossem próximos de um, a configuração do modelo neural foi considerada adequada. Estes parâmetros, juntamente com a raiz do erro médio quadrático (RMSE) foram utilizados para definir a topologia de RNA mais adequada para representar o processo de secagem. Para uma melhor visualização do ajuste do modelo neural também foi calculado, para cada vetor de verificação, o valor do erro de ajuste $\left(e_{i}=\right.$ valor $_{\text {real }}$-valor $\left._{\text {predito }}\right)$.

\section{RESULTADOS E DISCUSSÕES}

As configurações e os desempenhos durante a etapa de treinamento e verificação dos modelos neurais, que apresentaram o melhor ajuste aos dados de verificação, são apresentados na Tabela 2.

Tabela 2 - Resultados dos treinamentos das RNA's e da simulação com os dados de verificação

\begin{tabular}{|c|c|c|c|c|c|c|c|}
\hline \multirow[b]{2}{*}{ Topologia } & \multicolumn{3}{|c|}{ Treinamento } & \multicolumn{4}{|c|}{ Verificação } \\
\hline & $\begin{array}{c}\text { Parâmetros } \\
\text { originais/ } \\
\text { Parâmetros } \\
\text { efetivos }\end{array}$ & Épocas & SSE & $\mathbf{R}^{2}$ & $\begin{array}{c}\text { Equação da } \\
\operatorname{Reta}(\mathbf{y}=\mathbf{a x}+\mathbf{b})\end{array}$ & $S S E$ & $R M S E$ \\
\hline $\mathrm{A}(3 \times 3 \times 1)$ & $16 / 15,4$ & 32 & 0,000936 & 0,993 & $y=0,99 x+0,0017$ & 0,0196 & 0,0075 \\
\hline $\mathrm{B}(3 \times 4 \times 1)$ & $21 / 20,6$ & 13 & 0,000573 & 0,994 & $\mathrm{y}=0,99 \mathrm{x}-0,0008$ & 0,0662 & 0,0140 \\
\hline $\mathrm{C}(4 \times 4 \times 1)$ & $25 / 23,2$ & 18 & 0,001000 & 0,991 & $y=1 x-0,001$ & 0,0279 & 0,0089 \\
\hline $\mathrm{D}(3 \times 3 \times 1)$ & $16 / 12,6$ & 6 & 0,001510 & 0,999 & $y=1 x+0,00075$ & 0,0031 & 0,0030 \\
\hline
\end{tabular}

Os resultados da Tabela 2 mostram que todas as topologias de RNA's investigadas neste trabalho representaram bem o comportamento não-linear da cinética de secagem dos frutos de aroeira-vermelha. Os modelos neurais apresentaram o $\mathrm{R}^{2}$ próximo de um $(>0,99)$, o coeficiente linear da reta próximo de zero e o coeficiente angular da reta próximo de um. Além disto, os valores de RMSE foram um pouco acima do desvio padrão das saídas analisadas em cada topologia (desvio padrão de 0,003 para o teor de umidade, em base seca, e 0,004 para o adimensional de umidade). 
Para investigar as influências de alguns fatores na modelagem por RNA's (organização do banco de dados; número de neurônios de entrada; e função de ativação dos neurônios ocultos), algumas alterações foram realizadas na RNA de topologia B que é, segundo os trabalhos da literatura, a topologia mais utilizada na modelagem de processos de secagem. Primeiramente a umidade relativa do ar de secagem (UR) foi utilizada como entrada da rede (topologia $4 \times 4 \times 1$ ), sendo que os resultados não apresentaram melhorias significativas nos critérios de validação $\left(\mathrm{R}^{2}=0,9934, R M S E=0,014, \mathrm{y}=0,99 \mathrm{x}+0,0021\right)$ quando comparados com os critérios da Tabela 2 para a topologia B. Em seguida a função tangente hiperbólica foi substituída pela função sigmoidal (logsig no software MATLAB). Os resultados $\left(\mathrm{R}^{2}=0,994\right.$, $R M S E=0,0134, \mathrm{y}=0,99 \mathrm{x}+0,0045)$ indicam que as funções de ativação tangente hiperbólica e sigmoidal apresentaram resultados similares. Por fim, um segundo banco de dados foi organizado a partir dos ensaios de secagem da Tabela 1. Este foi constituído por oito experimentos de treinamento $(1,3,5,6,7,8,10$ e 11) e por três experimentos de verificação (2, 4 e 9), sendo que apresenta as seguintes características: valores máximos e mínimos das variáveis operacionais na etapa de treinamento; e todos os níveis de velocidade do ar, na etapa de treinamento. Os resultados $\left(\mathrm{R}^{2}=0,988, R M S E=0,019, \mathrm{y}=1 \mathrm{x}+0,0057\right)$ indicaram um grande efeito do banco de dados, sendo que o primeiro banco de dados foi mais eficiente na modelagem pois utilizou todos os níveis de temperatura do ar de secagem.

Conforme observado na Tabela 2, a topologia D foi a mais satisfatória entre todas as modelagens investigadas $\left(\mathrm{R}^{2}=0,999\right)$. Os pesos e viés encontrados no processo de treinamento desta topologia são apresentados na Tabela 3.

Tabela 3 - Viés e pesos entre os neurônios (topologia D)

\begin{tabular}{|c|c|c|c|c|}
\hline & \multicolumn{3}{|c|}{$\begin{array}{c}\text { Pesos entre os neurônios da camada de } \\
\text { entrada (I) e os neurônios da camada oculta } \\
\text { (H) }\end{array}$} & \multirow{2}{*}{$\begin{array}{c}\text { Pesos entre os neurônios da } \\
\text { camada oculta }(\mathrm{H}) \text { e os } \\
\text { neurônios da camada de } \\
\text { saída }(\mathrm{O})\end{array}$} \\
\hline & $I_{1}$ & $I_{2}$ & $I_{3}$ & \\
\hline$H_{1}$ & 0,5557 & $-0,0209$ & $-0,1153$ & 0,8049 \\
\hline $\mathrm{H}_{2}$ & 0,4193 & 0,1798 & $-0,0656$ & 0,8213 \\
\hline$H_{3}$ & $-0,3716$ & 0,1956 & $-0,1556$ & $-0,8041$ \\
\hline \multicolumn{5}{|c|}{ Viés dos neurônios ocultos (H) e neurônio de saída (O) } \\
\hline & & & $H_{3}$ & $O$ \\
\hline & & & $-0,1692$ & $-0,3791$ \\
\hline
\end{tabular}

Para uma melhor visualização dos resultados da verificação e comprovar o desempenho satisfatório do modelo neural desenvolvido na topologia $\mathrm{D}$, o ajuste deste modelo aos dados de verificação é representado na Figura 2 (a). Além disto, são apresentados os erros de ajuste em todos os pontos dos experimentos de verificação Figura 2 (b). 

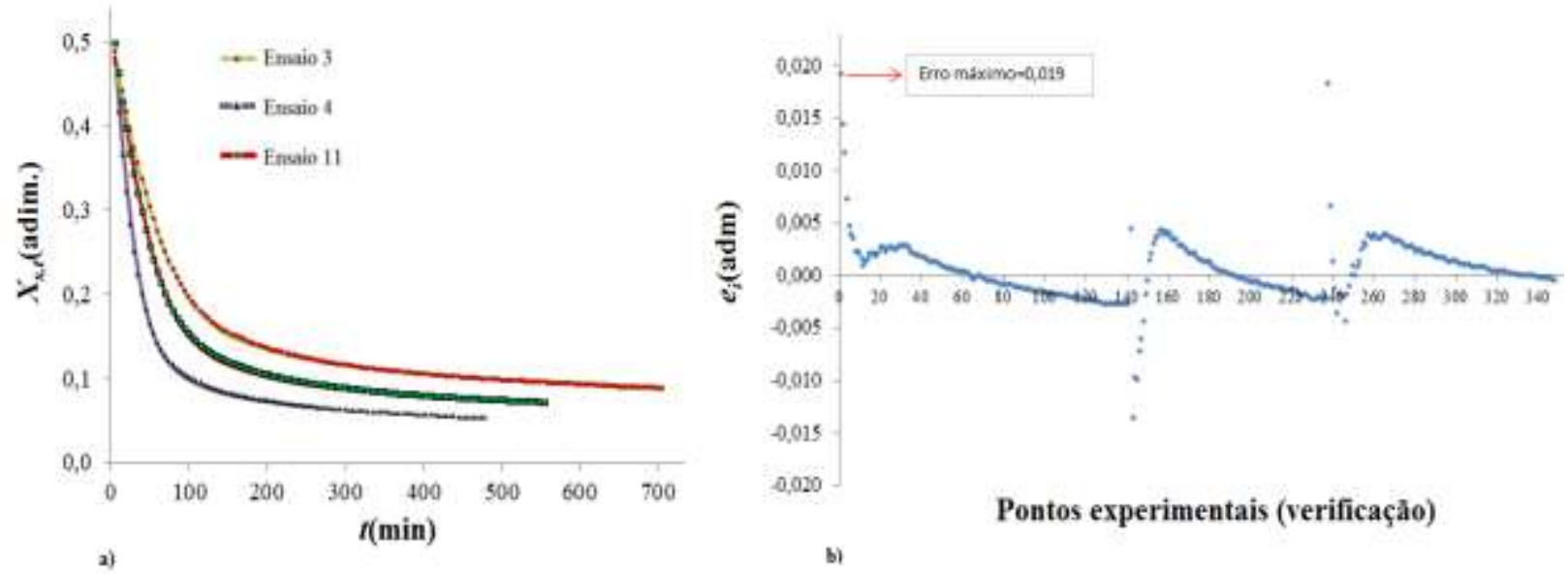

Figura 2 - a) Ajuste da RNA (topologia D) aos experimentos de verificação; b) Erro de ajuste versus experimentos de verificação.

Como já esperado, na Figura 2 (a) é observado que a saída desejada (dados pontuais) é muito próxima da saída da rede neural (linha contínua). Além disto, observa-se na Figura 2 (b) que o erro máximo obtido, entre todos os vetores, foi de 0,019. Apesar deste valor, verifica-se que a modelagem apresentou uma precisão (RMSE) próxima de 0,003 , que é exatamente igual ao desvio padrão estimado para o teor de umidade, em base seca. Como já relatado, estes resultados indicam o bom desempenho da modelagem por RNA, utilizando esta topologia, para predizer a cinética de secagem dos frutos de aroeira-vermelha nas condições operacionais estudadas neste trabalho.

\section{CONCLUSÕES}

Os resultados deste trabalho mostram que todas as topologias de RNA's investigadas representaram bem o comportamento não linear da cinética de secagem dos frutos de aroeiravermelha. Os modelos neurais apresentaram o $\mathrm{R}^{2}$ próximo de um $(>0,99)$, valores adequados de $R M S E$, o coeficiente linear da reta próximo de zero e o coeficiente angular da reta próximo de um. Foi observado que além da alta precisão, a grande vantagem das RNA's é a sua capacidade de prever o comportamento da secagem para uma faixa operacional e não apenas para uma única condição. As RNA's foram capazes de descrever uma série de experiências com precisão, não sendo limitada a um ensaio específico como ocorre nos modelos clássicos de secagem encontrados na literatura. Além disto, a faixa de condições experimentais do modelo neural pode ser expandida através da adição de novos conjuntos de experimentos de treinamento. Outras vantagens observadas foi a simplicidade e rapidez nas simulações via RNA's, uma vez que a estimativa da saída da RNA é realizada por simples operações aritméticas. É importante ressaltar que apesar das várias qualidades das RNA's na modelagem de processos de secagem, uma grande desvantagem observada neste trabalho foi a falta de conhecimento fenomenológico sobre a secagem que este tipo de abordagem proporcionou, pois os parâmetros das RNA's não possuem significado físico do processo. 


\section{REFERÊNCIAS BIBLIOGRÁFICAS}

AFZAL, T. M.; ABE, T. Simulation of moisture changes in barley during far infrared radiation drying. Computers and Electronics in Agriculture, v. 26, p. 137-145, 2000.

BALBAY, A.; ŞAHIN, O.; KARABATAK, M. An investigation of drying process of shelled pistachios in a newly designed fixed bed dryer system by using artificial neural network. Drying Technology: An International Journal, v. 29, p.1685-1696, 2011.

CEYLAN, I. Determination of drying characteristics of timber by using artificial neural networks and mathematical models. Drying Technology: An International Journal, v. 26, p. 1469-1476, 2008.

KAMINSKI, W.; TOMCZAK, E.; STRUMILL, P. Neurocomputing approaches to modelling of drying process dynamics. Drying Technology: An International Journal,v. 16, p. 967-992, 1998.

MOVAGHARNEJAD, K.; NIKZAD, M. Modeling of tomato drying using artificial neural network. Computers and Electronics in Agriculture, v.59, p.78-85, 2007.

PERAZZINI, H.; FREIRE, F. B.; FREIRE, J. T. Drying kinetics prediction of solid waste using semi-empirical and artificial neural network models. Chem. Eng. Technol., v. 36, n.7, p. 1193-1201, 2013.

SILVA, B. G. Modelagem e simulação do processo de secagem dos frutos de aroeiravermelha (Schinus terebinthifolius Raddi). 2013. 145 f. Dissertação (Mestrado em Engenharia Química) - Universidade Estadual de Campinas, Campinas, 2013.

SILVA, L. S.; REIS, G. G.; MANCINI, M. C.; CALÇADA, L. A. Determinação do coeficiente global de transferência de massa na secagem de sementes de agrião e agrião d'água em leito fixo e leito fluidizado: modelo a duas fases. Revista Universidade Rural: Série Ciências Exatas e da Terra. Seropédica, v.23, n.1-2, p. 18-33, 2004.

SINGH, J. N.; PANDEY, R. K. Neural network approaches for prediction of drying kinetics during drying of sweet potato. Agricultural Engineering International: CIGR Journal. v. 13, n.1, 2011.

TOPUZ, A. Predicting moisture content of agricultural products using artificial neural networks. Advances in Engineering Software, v. 41, p. 464-470, 2010. 